\title{
Oxygen releasing hydrogels for beta cell assisted therapy
}

Toftdal, Mette Steen; Taebnia, Nayere; Kadumudi, Firoz Babu; Andresen, Thomas Lars; Frogne, Thomas; Winkel, Louise; Grunnet, Lars Groth; Dolatshahi-Pirouz, Alireza

Published in:

International Journal of Pharmaceutics

Link to article, DOI:

10.1016/j.ijpharm.2021.120595

Publication date:

2021

Document Version

Publisher's PDF, also known as Version of record

Link back to DTU Orbit

Citation (APA):

Toftdal, M. S., Taebnia, N., Kadumudi, F. B., Andresen, T. L., Frogne, T., Winkel, L., Grunnet, L. G., \& Dolatshahi-Pirouz, A. (2021). Oxygen releasing hydrogels for beta cell assisted therapy. International Journal of Pharmaceutics, 602, [120595]. https://doi.org/10.1016/j.ijpharm.2021.120595

\section{General rights}

Copyright and moral rights for the publications made accessible in the public portal are retained by the authors and/or other copyright owners and it is a condition of accessing publications that users recognise and abide by the legal requirements associated with these rights.

- Users may download and print one copy of any publication from the public portal for the purpose of private study or research.

- You may not further distribute the material or use it for any profit-making activity or commercial gain

- You may freely distribute the URL identifying the publication in the public portal 


\title{
Oxygen releasing hydrogels for beta cell assisted therapy
}

\author{
Mette Steen Toftdal $^{\mathrm{a}, \mathrm{d}}$, Nayere Taebnia ${ }^{\mathrm{b}}$, Firoz Babu Kadumudi ${ }^{\mathrm{a}, *}$, Thomas Lars Andresen ${ }^{\mathrm{a}, \mathrm{b}}$, \\ Thomas Frogne $^{c}$, Louise Winkel ${ }^{\mathrm{d}}$, Lars Groth Grunnet ${ }^{\mathrm{d}}$, Alireza Dolatshahi-Pirouz ${ }^{\mathrm{a}, \mathrm{b}, \mathrm{e}, *}$ \\ ${ }^{a}$ Department of Health Technology, Technical University of Denmark, DK-2800 Kgs. Lyngby, Denmark \\ ${ }^{\mathrm{b}}$ Center for Intestinal Absorption and Transport of Biopharmaceuticals, Department of Health Technology, Technical University of Denmark, DK-2800 Kgs. Lyngby, \\ Denmark \\ ${ }^{\mathrm{c}}$ Department of Stem Cell Discovery, Novo Nordisk A/S, DK-2760 Mål $\phi v$, Denmark \\ ${ }^{\mathrm{d}}$ Department of Stem Cell Delivery \& Pharmacology, Novo Nordisk A/S, DK-2760 Målov, Denmark \\ ${ }^{\mathrm{e}}$ Radboud Institute for Molecular Life Sciences, Department of Dentistry - Regenerative Biomaterials, Radboud University Medical Center, Philips van Leydenlaan 25, \\ 6525EX Nijmegen, the Netherlands
}

\section{A R T I C L E I N F O}

\section{Keywords:}

Diabetes therapy

Oxygen release

Hydrogels

Calcium peroxide

\begin{abstract}
A B S T R A C T
Diabetes is a serious chronic disease, which globally affects more than 400 million patients. Beta cell therapy has potential to serve as an effective cure to type 1 diabetes and several studies have already shown promising results in this regard. One of the major obstacles in cell therapy, however, is the hypoxic environment that therapeutic cells are subjected to immediately after the transplantation. In this study, a new approach is presented, based on hydrogels composed of thiolated hyaluronic acid (tHA), 8-arm-Poly(ethylene glycol)-Acrylate (PEGA), and calcium peroxide (CPO) as an oxygen releasing system. Hydrogels containing 0, 7.5, and 30\% CPO were prepared, and the presence of CPO was confirmed via FTIR and Alizarin Red within the network. Oxygen release kinetics were monitored over time, and the results revealed that the hydrogels containing $30 \%$ CPO could release oxygen for at least $30 \mathrm{~h}$. All three combinations were found to be injectable and suitable for beta cell therapy based on their mechanical and rheological properties. Additionally, to investigate the functionality of the system, insulin secreting INS-1E reporter cell clusters were encapsulated, and their viability was evaluated, which showed that $\mathrm{CPO}$ incorporation enhanced cell survival for at least three days.
\end{abstract}

\section{Introduction}

Diabetes is a serious disease which globally affects more than 400 million patients - and the number is constantly increasing (Association, 2018; Organization, 2016). It was recently estimated that 451 million adults (age 18-99 years) were suffering from diabetes in 2017 and the number is predicted to increase to 693 million by 2045 (Cho et al., 2018). People suffering from type 1 diabetes (T1D) are in critical need of daily exogenous delivery of insulin to survive. Even though different insulin therapies are currently available on the market, their promise is severely hampered by challenges such as managing the daily glycemic control (Rezania et al., 2014). Indeed; poor glycemic control is associated with several long-term complications such as diabetic nephropathy, cardiovascular diseases, and retinopathy (Fowler, 2008; Group, 2005). According to the World Health Organization (WHO), 3.7 million people died from diabetes or diabetes-related complications in 2012
(Organization, 2016). In addition to increased fatality, diabetes is associated with tremendous economic costs and poses serious challenges to public health in need of a solution.

One of the emerging solutions rides on advances in cell therapy and tissue engineering (TE). The merger between these two fields holds immense promise not only for treatment, but also for finding a functional T1D cure (Zamboni and Collins, 2017). Cell therapy is all about the cellular material being transplanted or injected into the patient body to treat a specific disease. Despite promising results, there are still critical issues, which needs to be addressed before this newlyestablished method can unleash its promise. One of the major challenges in this path is the low retention rate and cell survival and thus limited therapeutic effects (Haraguchi et al., 2012). Cells delivered by syringe-based injection methods, are subjected to mechanical shear stress upon injection; something that may compromise their viability, proliferation rate, and morphology (Agashi et al., 2009), and therefore

\footnotetext{
* Corresponding authors at: Department of Health Technology, Technical University of Denmark, DK-2800 Kgs. Lyngby, Denmark (A. Dolatshahi-Pirouz and F.B. Kadumudi).

E-mail addresses: fbka@dtu.dk (F.B. Kadumudi), aldo@dtu.dk (A. Dolatshahi-Pirouz).
} 
they must be mechanically shielded in order to ensure proper survival rates. In TE, cells are either seeded on or encapsulated in a threedimensional (3D) construct composed of biomaterials. These scaffolds serve as carrier systems for cells during injection or transplantation providing protection and physical support. Additionally, incorporating essential growth factors or specific stimuli into these scaffolds can provide a template for cell interaction and for controlling cell fate. Depending on the intended application, the scaffolds can positively affect the cell survival, proliferation, differentiation, and even vascularization (Derakhshanfar et al., 2018; Haraguchi et al., 2012). Lastly, an ideal scaffold should protect the transplanted cells from the host immune response (Weber et al., 2009).

One avenue towards fabricating these scaffolds is by cross-linking polymers into highly hydrated 3D network called hydrogels, that due to their high water content can mimic the microenvironment of the natural extracellular matrix (ECM). These biomaterials have sparked a wave of excitement in recent years, due to their broad application portfolio within the area of biomedical engineering. Hydrogels are capable of being engineered as injectable, conductive, self-healing, or stimuli-responsive biomaterials and may thus be used in extensive range of applications (Mahinroosta et al., 2018). Injectable in situ forming hydrogel systems allow minimized transplantation morbidity and thereby make the therapy less invasive (Thambi et al., 2017). The natural occurring polymer, hyaluronic acid (HA), found in the ECM of several human tissues, has been widely studied as a backbone of hydrogel scaffolds. HA has been found to influence cellular behavior and thereby positively affect cell adhesion, survival, migration and proliferation (Wolf and Kumar, 2019). HA alone possesses limited mechanical properties and degrades readily under physiological conditions, which can be improved through chemical cross-linking or by introducing chemical modification into the polymer (Segura et al., 2005). One of the most promising approaches is thiol modification of HA (tHA) that opens new covalent cross-linking possibilities with prolonged stabilities (Zamboni et al., 2020). In this regard, tHA that chemical cross-links with 8-arm-PEG-acrylate (8-arm-PEGA) via a thiol-ene reaction PEGA provides a stable system for several days in vitro before it is degraded via hydrolysis (D'souza and Shegokar, 2016; Hasany et al., 2018). One type of tHA is Glycosil®, which is a biodegradable, GMP-qualified and commercialized hydrogel system (Zarembinski and Skardal, 2018).

Concurrently, encapsulated cells in hydrogel systems, must receive sufficient amounts of oxygen and nutrients to survive and function. For instance, when it comes to insulin producing beta cells, the oxygen partial pressure $\left(\mathrm{pO}_{2}\right)$ on the surface of an average-size islet must be approx. $35 \mathrm{mmHg}$ to maintain full viability. In vivo, pancreatic islets receive up to $15 \%$ of the pancreatic blood supply despite occupying only $1 \%$ of the total mass of the pancreas (Colton, 2014). This indicates that oxygen is readily available for islets at physiological conditions to maintain their viability and functionality (Komatsu et al., 2018). Oxygen limitations may, however, occur during transplantation due to the lack of vascularization. In a previous study, human islets were transplanted into streptozotocin-induced diabetic nude mice under the kidney capsule (Davalli et al., 1995), and a significant islet loss was observed after transplantation. Indeed, oxygen diffusion becomes heavily compromised over a distance of $100-200 \mu \mathrm{m}$ and the resulting hypoxic condition may become even worse in case of encapsulation - especially for islets in the central part of the construct (Colton, 2014; Gholipourmalekabadi et al., 2016; Wenger et al., 2015). Several researchers have so far tried to solve the hypoxia-related problems connected to transplantation of cells by developing oxygen releasing systems (Alemdar et al., 2017; Camci-Unal et al., 2013; Mouré et al., 2019) or by continuously delivering oxygen to the transplanted cells from an external source (Ludwig et al., 2017). One way to generate an oxygen releasing hydrogel is by incorporating solid peroxides, such as calcium peroxide (CPO), into the system. CPO has been reported to release oxygen in a controlled manner within an aqueous environment such as GelMa and alginate hydrogels (Alemdar et al., 2017; McQuilling et al.,
2017; Montesdeoca et al., 2020), as it decomposes upon contact with water to form oxygen (Camci-Unal et al., 2013).

To address the established scientific challenges within beta cell therapy the current study aims to develop an oxygen releasing hydrogel system, which supports encapsulation of beta cell clusters mechanically and maintains the viability of the 3D-encapsulated clusters by providing them with appropriate amount of oxygen. In more details, the developed hydrogel system was composed of Glycosil ${ }^{\circledR}$ tHA chemically crosslinked with 8-arm-PEGA and infused with CPO to enable a prolonged oxygen release (Fig. 1).

\section{Materials and methods}

\subsection{Hydrogel fabrication}

To obtain an oxygen releasing hydrogel, $\mathrm{CPO}$ was incorporated into a tHA-8-arm-PEGA hydrogel system. First, a stock solution of $1.1 \%(\mathrm{w} / \mathrm{v})$ tHA (300 kDa, Gycosil, HyStem Hydrogel Kit, ESI BIO, CA, USA) was prepared in degassed water. Desired amount of tHA solution was then gently mixed with Dulbecco's phosphate-buffered saline (DPBS) without calcium and magnesium (Sigma Aldrich, Germany), 8\% (w/v) 8-armPEGA (Creative PEGworks, NC, USA), and varying concentrations of CPO (Sigma Aldrich, Germany). The final concentrations of the components were $0.5 \%(\mathrm{w} / \mathrm{v})$ tHA, $0.8 \%(\mathrm{w} / \mathrm{v}) 8$-arm-PEGA and $0,7.5$, and $30 \%\left(\mathrm{w} / \mathrm{w}_{\mathrm{tHA}}\right.$ ) CPO. The concentration of tHA and 8-arm-PEGA were kept constant in all hydrogel combinations and the amount of CPO was based on the amount of tHA.

\subsection{Characterization of hydrogels}

Fourier-transform infrared spectroscopy (FTIR) and Alizarin Red staining were employed to investigate successful incorporation and distribution of CPO into the hydrogels and to monitor its stability through time. Both experiments were carried out on hydrogels with a volume of $10 \mu \mathrm{L}$ containing three different concentrations of CPO; $0 \%$, $7.5 \%$, and $30 \%\left(\mathrm{w} / \mathrm{w}_{\mathrm{tHA}}\right)$. Hydrogels were manufactured and incubated at $37^{\circ} \mathrm{C}$ in DPBS. They were analyzed using FTIR and Alizarin Red at day $1,3,5$, and 7. For FTIR analysis, samples were washed in deionized water and lyophilized for $24 \mathrm{~h}$. The FTIR spectra for each hydrogel condition were then obtained using Spectrum 100 FTIR spectrometer (PerkinElmer, MA, USA). Before the samples were analyzed, a background subtraction was conducted. All FTIR spectra were recorded from 4000 to $530 \mathrm{~cm}^{-1}$ using 16 scans at a resolution of $4 \mathrm{~cm}^{-1}$. After recording, the spectra were baseline-corrected and normalized using PerkinElmer Spectrum software. Additionally, the FTIR spectrum of pure CPO was obtained for comparison.

Alizarin Red staining was applied to qualify calcium present in the hydrogels. A solution of $2 \%(\mathrm{w} / \mathrm{v})$ Alizarin Red (Sigma Aldrich, Germany) was prepared in calcium and magnesium-free DPBS. The $\mathrm{pH}$ was then adjusted to $4.2 \pm 0.1$ using $1 \mathrm{M} \mathrm{HCl}$ and the solution was filtered through $0.45 \mu \mathrm{m}$ syringe filter. Prior to staining, hydrogels were washed twice with DPBS without calcium and magnesium and incubated in the Alizarin Red solution in the absence of light for $1 \mathrm{~h}$ and washed twice with DPBS. They were further incubated in dark overnight in order to remove excess dye. Finally, the samples were imaged using bright field microscopy (Carl Zeiss Axioscope 40, Germany) the following day and the color intensity was quantified using ImageJ 2.0.

\subsection{Scanning electron microscopy}

The morphology and pore size of the three different hydrogel conditions were assessed using scanning electron microscopy (SEM). $200 \mu \mathrm{L}$ hydrogels containing $0,7.5$, and $30 \% \mathrm{CPO}$ were prepared and incubated for $14 \mathrm{~h}$ to allow swelling (Hasany et al., 2018). After incubation, the hydrogels were washed twice with Milli-Q water and lyophilized for 24 h. They were then cut to enable cross-section visualization and coated 

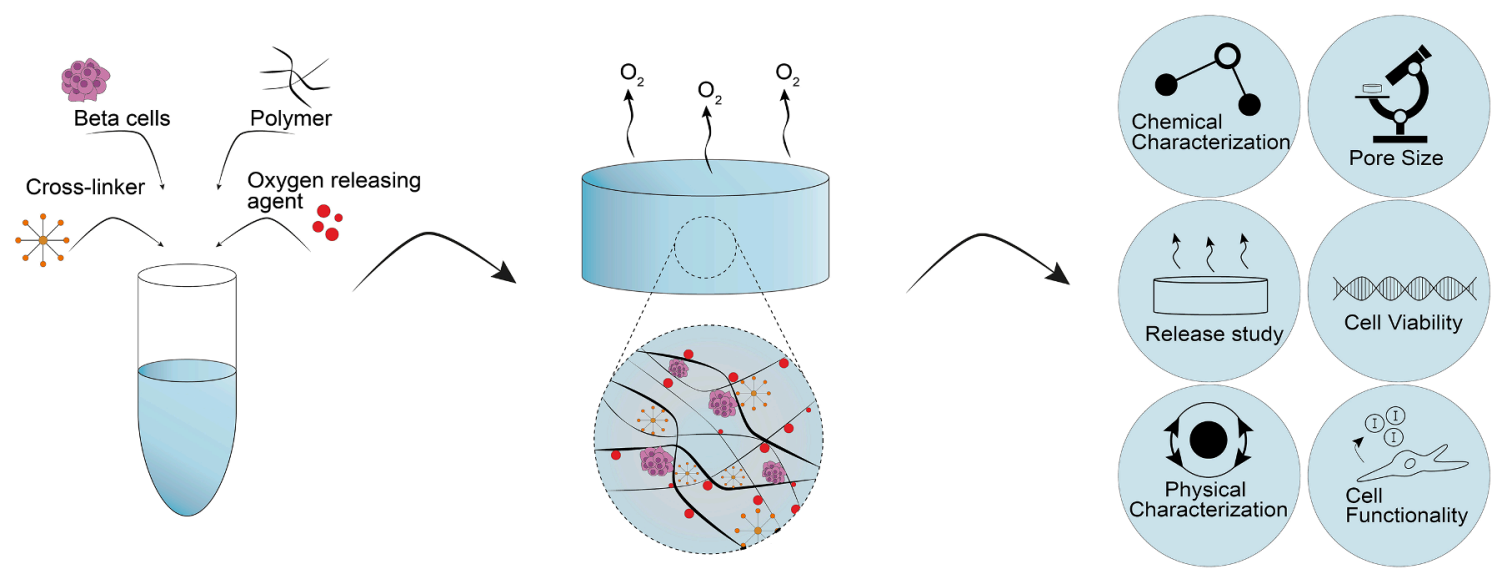

Fig. 1. Schematic illustration of the concept of study. Hydrogels consisting of hyaluronic acid (polymer), 8-arm-PEGA (cross-linker), and calcium peroxide (oxygen releasing agent) were manufactured and tested in terms of chemical and physical properties, as well as hydrogel-cell interactions, cell viability and functionality.

with gold particles using a Q150R Plus Rotary Pumped Coater (Quorum Technologies, UK) prior to imaging. The microstructure of prepared hydrogels was subsequently investigated using SEM-Quanta FEG-250 (FEI Company, OR, USA) operated with an acceleration voltage of $4 \mathrm{kV}$. The images were further analyzed using ImageJ 2.0.

\subsection{Oxygen release study}

An oxygen release study was conducted to investigate the release kinetics of oxygen from the developed hydrogel systems. To this end, a hypoxia chamber was designed and manufactured (Supplementary Fig. S1) to create a hypoxic environment. Before the release study was initiated, nitrogen gas was continuously perfused through the chamber to obtain an oxygen free environment.

The release kinetics of the CPO laden hydrogels were then determined using FirestingO2 fiber-optic oxygen meter, oxygen sensor spots, bare optical fibers, and logged by Oxygen Logger software (Pyroscience, Germany). Before the experiment was started, the sensor was calibrated through a one-point calibration at atmospheric oxygen level. $30 \mu \mathrm{L}$ hydrogels containing $0 \%, 7.5 \%$, and $30 \%$ CPO were individually placed in $3 \mathrm{~mL}$ calcium and magnesium-free DPBS and $100 \mathrm{U} / \mathrm{mL}$ catalase (obtained from bovine liver, 2000-5000 U/mg protein, Sigma Aldrich, Germany) in the hypoxia chamber. A vial containing only DPBS and catalase was used as control and for background subtraction. To quantify the dissolved oxygen, an oxygen sensor was placed at the bottom of each vial. Area under the release curve (AUC) from 0 to $35 \mathrm{~h}$ was determined for further comparison between the three conditions.

\subsection{Mechanical properties}

To evaluate the mechanical compression behavior of the hydrogels, $20 \mu \mathrm{L}$ hydrogels containing $0,7.5$, and $30 \% \mathrm{CPO}$ were prepared in cylindrical shape and incubated in DPBS for $14 \mathrm{~h}$ at $37^{\circ} \mathrm{C}$ to allow swelling (Hasany et al., 2018) before the mechanical test was conducted. The compression test was carried out using Instron mechanical tester (model 5967 , UK) with a constant compression rate of $0.5 \mathrm{~mm} / \mathrm{min}$. The tests were performed with a $50 \mathrm{~N}$ load cell, and each combination was replicated five times. The compressive modulus was then calculated from the slope of the stress/strain curve between 15 and $25 \%$ strain.

\subsection{Rheological properties}

The rheological properties of the polymer solutions $(0,7.5$, and $30 \%$ $\mathrm{CPO})$ were investigated to monitor their gelation kinetics and shear thinning properties, using a Discovery Hybrid HR-2 Rheometer (TA Instruments, DE, USA) and a $25 \mathrm{~mm}$ parallel plate geometry at $25{ }^{\circ} \mathrm{C}$. The loading gap was fixed at $800 \mu \mathrm{m}$ to load $180 \mu \mathrm{L}$ polymer solution. The gap distance was then decreased to $300 \mu \mathrm{m}$ to study the rheological properties of the solutions. The cross-linking onset in terms of gelation point was estimated over 20 min using an oscillation time test performed under the angular frequency of $50 \mathrm{rad} / \mathrm{s}$ and $1 \%$ strain. The shearthinning behavior was analyzed using a flow sweep test under the increasing shear rate $(0.001$ to $10001 / \mathrm{s})$.

\subsection{Cell culturing and cluster formation}

In this study, insulin secreting INS-1E reporter cells were used for all cell experiments. The INS-1E cells are transfected with the sequence of Gaussia luciferase. This genetic modification yields a reporter cell line with correlated secretion of insulin and luciferase (Burns et al., 2015), (Supplementary Fig. S2). Cells were cultured at $37^{\circ} \mathrm{C}, 5 \% \mathrm{CO}_{2}$, and $90 \%$ humidity. Every 4th day the growth medium was changed which consisted of RPMI 1460 (Gibco, Thermofisher, MA, USA), 10\% heatinactivated Fetal Bovine Serum ((Gibco, Thermofisher, MA, USA), 100 $\mathrm{U} / \mathrm{mL}$ penicillin (Gibco, Thermofisher, MA, USA), $100 \mu \mathrm{g} / \mathrm{mL}$ streptomycin (Gibco, Thermofisher, MA, USA), and $50 \mu \mathrm{M}$ 2-mercaptoethanol (Gibco, Thermofisher, MA, USA). To mimic the cluster appearance of pancreatic islet clusters, INS-1E cell clusters were formed from INS to $1 \mathrm{E}$ single cells. To form clusters, $7.5 \times 10^{6}$ single cells were seeded in in 10 $\mathrm{mL}$ growth medium in a non-adherent $10 \mathrm{~cm}$ petri dish before adding 10 $\mu \mathrm{M}$ Rock-Inhibitor (Roche, Germany) and $50 \mu \mathrm{g} / \mathrm{mL}$ DNase (Sigma Aldrich, Germany). Cells were cultured for two days at $70 \mathrm{rpm}$ to obtain approx. 800 islet equivalent (IEQ)/mL.

\subsection{Cell encapsulation}

Two days after cluster formation INS-1E clusters were harvested and counted by an Automatic Islet Cell Counter (BioRep Technologies, FL, USA) and were encapsulated in hydrogels with a final cluster density of $10 \mathrm{IEQ} / \mu \mathrm{L}$ hydrogel. Cell clusters were mixed with tHA prior to the addition of 8-arm-PEGA and CPO. After cross-linking the cell-laden hydrogels were incubated at $37{ }^{\circ} \mathrm{C}, 5 \% \mathrm{CO}_{2}$, and $90 \%$ humidity in growth medium containing $100 \mathrm{U} / \mathrm{mL}$ catalase prior to other cell experiments.

\subsection{Live/dead viability assay}

To evaluate cell viability of the encapsulated clusters in hydrogels containing $0,7.5$, and $30 \% \mathrm{CPO}$, a live/dead staining assay was conducted on day 1 and 3 using $10 \mu \mathrm{L}$ cell-laden hydrogels. LIVE/DEAD Viability/Cytotoxicity Kit (Invitrogen Thermofisher, MA, USA) was used to carry out the viability staining. A fresh dye solution consisting of 
RPMI 1640, $5 \mu \mathrm{g} / \mathrm{mL}$ calcein acetoxymethyl, and $5.1 \mu \mathrm{g} / \mathrm{mL}$ ethidium homodimer-1 (EthD-1), was prepared. Encapsulated clusters were washed with DPBS before staining. The samples were then incubated in dark at $37^{\circ} \mathrm{C}$ for $20 \mathrm{~min}$ before imaging by Nikon inverted Spinning Disk confocal Ti2 microscope (Nikon, Japan) equipped with Nikon NIS Elements Imaging Software (Nikon, Japan). Calcein and EthD-1 were excited at wavelengths of 488 and $517 \mathrm{~nm}$, respectively. To yield 3D images, stacks of $1 \mu \mathrm{m}$ thick were obtained in z-direction. Lastly, to visualize the distribution of encapsulated clusters, samples were observed at lower magnification using a wavelength of $488 \mathrm{~nm}$ and $2 \mu \mathrm{m}$ z-stacks over $300 \mu \mathrm{m}$ of the hydrogel.

\subsection{Cell functionality}

To investigate the in vitro functionality of the cells in terms of glucose-stimulated insulin secretion, encapsulated and nonencapsulated clusters were assayed using a perifusion setup to determine whether their functionality and responsiveness were affected due to the encapsulation in the hydrogel systems. The BioRep Perifusion system PERI5-230 (BioRep Technologies, FL, USA) is a multi-channel apparatus allowing parallel perifusion of 12 independent samples and was utilized in this study. The perifusion setup worked by exposing the clusters to different inputs over time and collecting the secretory outputs in defined timeframes. Luciferase secretion was used as a surrogate protein for insulin secretion and it was analyzed at three different glucose-containing inputs to assess and compare the cluster functionality and responsiveness of clusters encapsulated for 1 day within the hydrogels containing $0,7.5$, or $30 \% \mathrm{CPO}$. The perifusion system was primed and the columns were packed according to the manufacturer's guidelines. All inputs contained a buffer solution consisting of KrebsRinger Buffer with HEPES (KRBH, VWR, PA, USA) buffer, $2 \mathrm{mM}$ glutaMAX (Gibco, Thermofisher, MA, USA), and 0.2\% (w/v) human serum albumin (Sigma Aldrich, Germany). The KRBH buffer consisted of 119 $\mathrm{mM} \mathrm{NaCl}, 4.7 \mathrm{mM} \mathrm{KCl}, 2.5 \mathrm{mM} \mathrm{CaCl}_{2}, 1.2 \mathrm{mM} \mathrm{MgSO}_{4}, 1.2 \mathrm{mM} \mathrm{KH}_{2} \mathrm{PO}_{4}$, and $20 \mathrm{mM}$ HEPES. A flow rate of $100 \mu \mathrm{L} / \mathrm{min}$ was applied and kept constant during the whole experiment. Firstly, the INS-1E clusters were exposed to the KRBH solution supplemented with $2 \mathrm{mM}$ glucose (low glucose) (Sigma Aldrich, Germany) to bring the insulin secretion to a basal level. Secondly, the clusters were exposed to $20 \mathrm{mM}$ glucose (high glucose) dissolved in the KRBH solution to stimulate insulin and luciferase secretion. Following this, clusters were again exposed to the low glucose solution to lower secretion. All clusters were then challenged with high glucose supplemented with $500 \mu \mathrm{M}$ isobutylmethylxanthine (IBMX) (Sigma Aldrich, Germany) and $10 \mu \mathrm{M}$ forskolin (Tocris Bioscience, UK) serving as a positive control. Lastly, the cells were exposed to low glucose condition, to return to basal secretion. During the experiment, all input solutions and columns were kept at $37^{\circ} \mathrm{C}$, whereas the perifusates were kept at $4{ }^{\circ} \mathrm{C}$ to preserve the integrity of luciferase. All secretory outputs were collected at defined intervals from 2 to $22 \mathrm{~min}$ and further analyzed for their luciferase activity.

\subsection{Luciferase quantification}

To quantify the amount of released luciferase, the flow-through was collected and analyzed using Nano-Glo Luciferase Assay (Promega, WI, USA). Nano-Glo Luciferase Assay substrate was prepared and mixed with the samples according to manufacturer's guidelines. After $10 \mathrm{~min}$ the samples were analyzed by their luminescence intensity using Spectramax M4 Microplate Reader (Molecular Devices, CA, USA). The luciferase activity was plotted against time and normalized to the number of perifused clusters. To compare the total amount of glucoseinduced luciferase produced during the high glucose challenge, the AUC from 120 - $215 \mathrm{~min}$ was calculated for each condition (nonencapsulated, $0,7.5$, and $30 \% \mathrm{CPO}$ ). Lastly, the delay of luciferase secretion when going from $20 \mathrm{mM}$ to $2 \mathrm{mM}$ glucose was quantified for encapsulated clusters and compared to the secretion delay of non- encapsulated clusters.

\subsection{Statistics}

All data were presented as mean \pm standard deviation. One-way ANOVA test was conducted to analyze the variance of the results obtained from the oxygen release study $(n=3)$, mechanical compression study $(n=5)$, pore size analysis $(n=4)$, and functionality study $(n=3)$. Tukey's multiple comparisons test was conducted in conjunction with the one-way ANOVA to evaluate any significant differences among the means of the sample conditions. A p-value $<0.05$ was considered as a significant difference.

\section{Results}

\subsection{Fabrication and characterization of oxygen-releasing hydrogels}

FTIR spectroscopy and Alizarin Red staining were used to investigate the incorporation of $\mathrm{CPO}$ and its stability within the hydrogels over time. The FTIR spectra obtained from three independent hydrogels $(0$, 7.5, and 30\% CPO) are presented in Fig. 2D. The presence of 8-armPEGA was confirmed in all three hydrogel conditions by the presence of a $\mathrm{C}=\mathrm{O}$ stretching peak at $1720 \mathrm{~cm}^{-1}$, two $\mathrm{C}-\mathrm{O}$ asymmetric bending peaks at $1300 \mathrm{~cm}^{-1}$ and $1250 \mathrm{~cm}^{-1}$ and $\mathrm{C}-\mathrm{O}-\mathrm{C}$ stretching peak at $1039 \mathrm{~cm}^{-1}$ (Fig. 2D). These peaks were in accordance with the peaks previously observed from pure 8-arm-PEGA and the cross-linked tHA-8arm-PEGA hydrogel, confirming the successful cross-linking of the hydrogels via covalent linkage between thiol $(\mathrm{SH})$ group present in tHA and acrylate groups present in 8-arm-PEGA (Fig. 2A-C) (Chung et al., 2016; Jain et al., 2017). The FTIR spectrum of CPO shows a broad peak between 1300 and $1600 \mathrm{~cm}^{-1}$, a broad peak around $980 \mathrm{~cm}^{-1}$, and a peak at $864 \mathrm{~cm}^{-1}$ corresponding to $\mathrm{CO}_{3}^{2-}$ stretching vibration, stretching vibrations of $\mathrm{Ca}-\mathrm{O}$ and $\mathrm{O}-\mathrm{O}$ stretching vibration of peroxide, respectively (Khorshidi et al., 2020; Rastinfard et al., 2018). After incorporation of CPO into the hydrogels, the C-O-C stretching peak of tHA at $1039 \mathrm{~cm}^{-1}$ was slightly shifted to $1021 \mathrm{~cm}^{-1}$ and the intensity of this peak increased due to the interaction of Ca-O with tHA (Supplementary Fig. S3). The peak intensity was increased with increasing amounts of CPO confirming successful incorporation of CPO. Further, the stability of CPO in the hydrogels was examined using FTIR over a 7 days incubation period. As can be seen from Fig. 2D, the peak at $1021 \mathrm{~cm}^{-1}$ corresponding to Ca-O decreased slowly over time. This peak became stable and comparable with tHA after 3 days for $7.5 \% \mathrm{CPO}$ and after 5 days for $30 \% \mathrm{CPO}$. These results indicates that $\mathrm{CPO}$ was converted to $\mathrm{O}_{2}$ and $\mathrm{Ca}(\mathrm{OH})_{2}$ after reacting with water. Moreover, the hydroxide conversion was further evidenced by the increased intensity of the broad $-\mathrm{OH}$ stretching peak between 3000 and $3500 \mathrm{~cm}^{-1}$ with increasing incubation days for $7.5 \%$ and $30 \%$ CPO incorporated hydrogels. On the other hand, the pure hydrogels system without $\mathrm{CPO}$ showed decrease in intensity of $-\mathrm{OH}$ stretching peak due slight degradation of the polymer backbone. These results illustrate that CPO was successfully incorporated in both CPOladen hydrogels and that $\mathrm{CPO}$ remained longer in the system containing 30\% CPO compared to $7.5 \% \mathrm{CPO}$.

To further assess the incorporation of $\mathrm{CPO}$, Alizarin Red staining was conducted at day 1, 3, 5, and 7 (Fig. 3A). Alizarin Red reacts with and stains calcium and thereby allows qualification of calcium present in the hydrogels and therefore also CPO. Hydrogels without CPO appeared, as expected, transparent at all time-points. Both $7.5 \%$ and $30 \% \mathrm{CPO}$ remained red at all four time points and calcium was observed to be distributed throughout the hydrogel, which is necessary to obtain an even oxygen release throughout the system. The color did not vanish during 7 days of incubation; hence confirming that calcium remained in the hydrogels after one week. The color intensity was found to be the highest for the hydrogels containing 30\% CPO when compared to samples containing 7.5 and $0 \% \mathrm{CPO}$ (Fig. 3B), supporting the increased concentration of CPO from $7.5 \%$ to $30 \%$. 

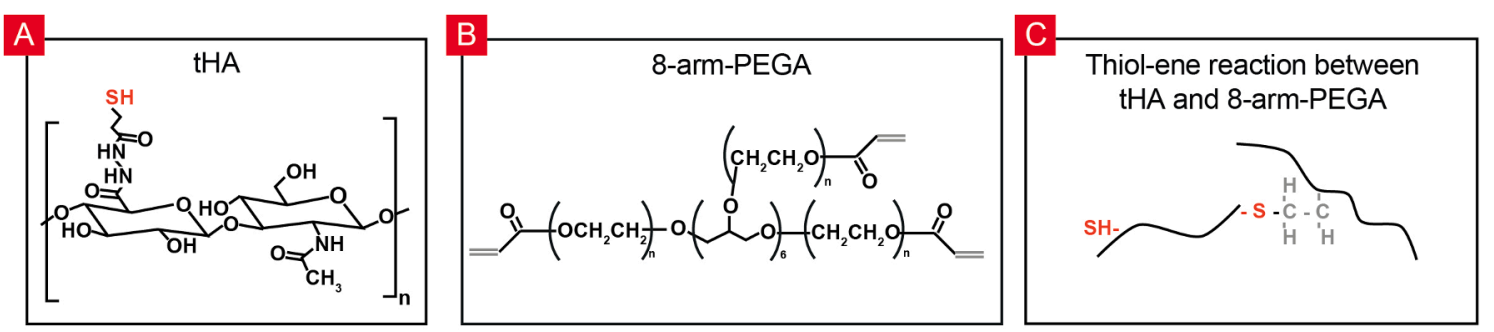

D
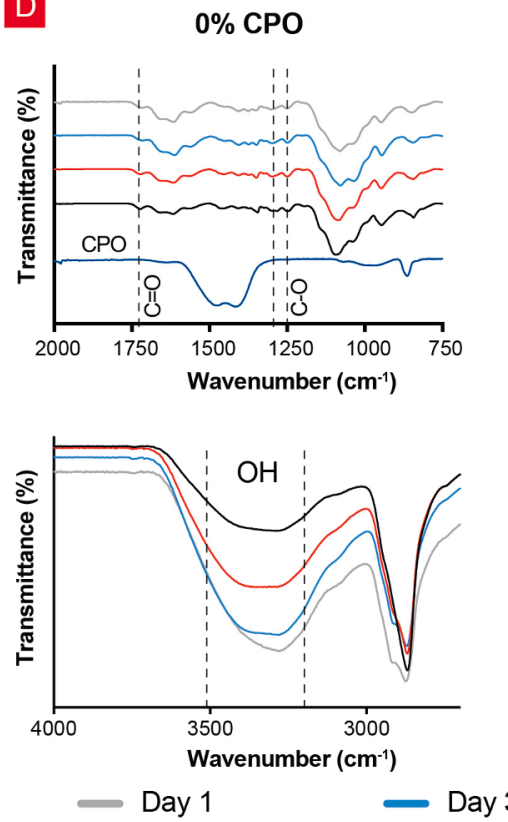

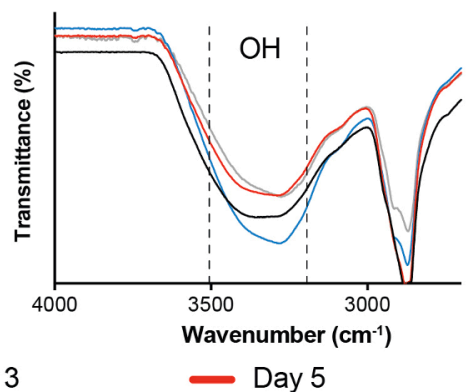

$7.5 \% \mathrm{CPO}$

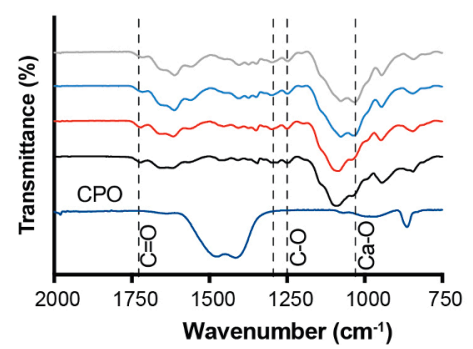

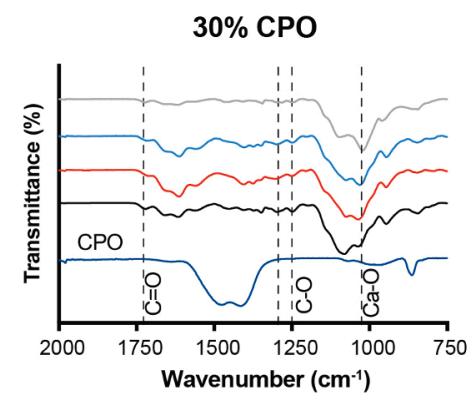

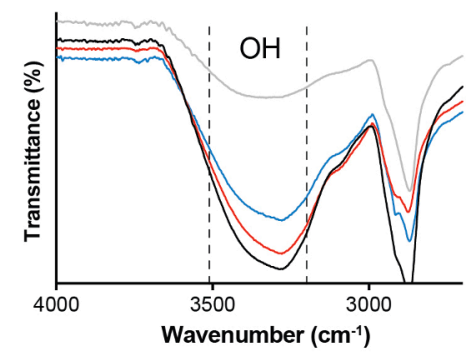

Day 7

$\longrightarrow \mathrm{CPO}$

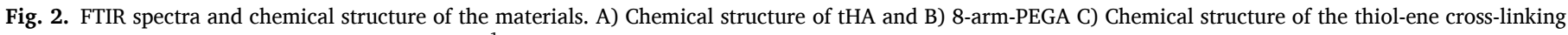

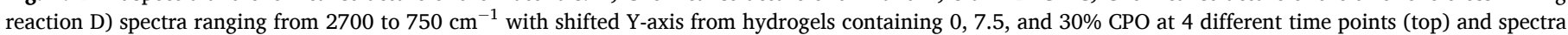

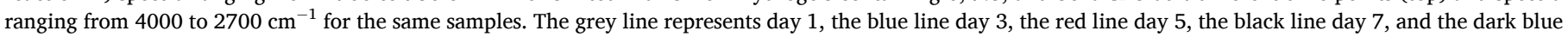
line represents pure CPO.

An oxygen release study was carried out to characterize the release kinetics of oxygen from the designed hydrogel systems (Fig. 3C). The release curves from Fig. 3C, displays the oxygen concentration as a function of time demonstrating that hydrogels containing 30\% CPO continuously released oxygen for $30 \mathrm{~h}$, whereas hydrogels containing 7.5\% CPO stopped releasing this vital element after $10 \mathrm{~h}$ of incubation (Fig. 3C). A burst release was initially observed from all CPOincorporated hydrogels. Although a background sample (containing DPBS and catalase) was subtracted from all three release curves presented in Fig. 3C, hydrogels containing 0\% CPO showed a minor initial increase in oxygen concentration within the first $4 \mathrm{~h}$. This initial increase can be explained by a minor oxygen contamination introduced upon addition of hydrogels prior to the experiment, since the hydrogels could not be added under completely hypoxic conditions.

Pore size, interconnectivity, and porosity are among the key features to support cell survival and function when it comes to 3D-encapsulation. Therefore, SEM images were taken to analyze the pore size and interconnectivity of the hydrogel systems. The average pore size for hydrogels containing $0,7.5$, and $30 \%$ CPO was found to be $448 \pm 142,420 \pm$ 172 , and $409 \pm 163 \mu \mathrm{m}^{2}$, respectively (Fig. 3E). No statistically significant differences were found between the three hydrogels. From the cross-section SEM images, it is also evident that the pores were interconnected (Fig. 3D) and this is of great importance for ensuring optimal and efficient fluid exchange between encapsulated cells and the surrounding environment. There are, however, few non-connecting pores in the images, which are most likely a consequence of the sample preparation.

\subsection{Mechanical and rheological properties}

The three hydrogel combinations were characterized in terms of their mechanical and rheological properties, to investigate their suitability for beta cell therapy.

A mechanical compression test was conducted to investigate the effect of CPO incorporation on the mechanical properties of hydrogels such as Young's modulus and toughness. As stated above, the backbone of the cross-linked network in this study is composed of tHA and 8-armPEGA due to their many beneficial properties, including relatively low compressive modulus, similar to that of native pancreatic tissue. Stress/ strain curves (Fig. 4A) were obtained for each combination and the compressive modulus, ultimate stress, breakage strain, and toughness were calculated accordingly. As expected, hydrogels without CPO had a relatively low compressive modulus $(3.0 \pm 1.8 \mathrm{kPa})$ (Fig. $4 \mathrm{~A})$. The incorporation of 7.5 and $30 \%$ CPO slightly strengthened the hydrogel systems and resulted in compressive modulus of $4.2 \pm 1.9$ and $4.0 \pm 0.8$ $\mathrm{kPa}$, respectively. However, all three hydrogel conditions still had relatively low compressive modulus. We envision that this could support beta cells survival by providing them with a native-like microenvironment in terms of stiffness, since the young's modulus of native pancreatic tissue is approx. $3 \mathrm{kPa}$ (Sugimoto et al., 2014). Toughness, which is a representative of a hydrogels resistance to fracture when stressed, was calculated as the area under the stress/strain curves and found to be 0.8 $\pm 0.2,1.4 \pm 0.3$, and $1.8 \pm 0.5 \mathrm{~kJ} / \mathrm{m}^{3}$ for hydrogels containing $0,7.5$, and $30 \% \mathrm{CPO}$, respectively (Fig. 4A). CPO laden hydrogels showed a significantly greater toughness compared to hydrogels without CPO. In 


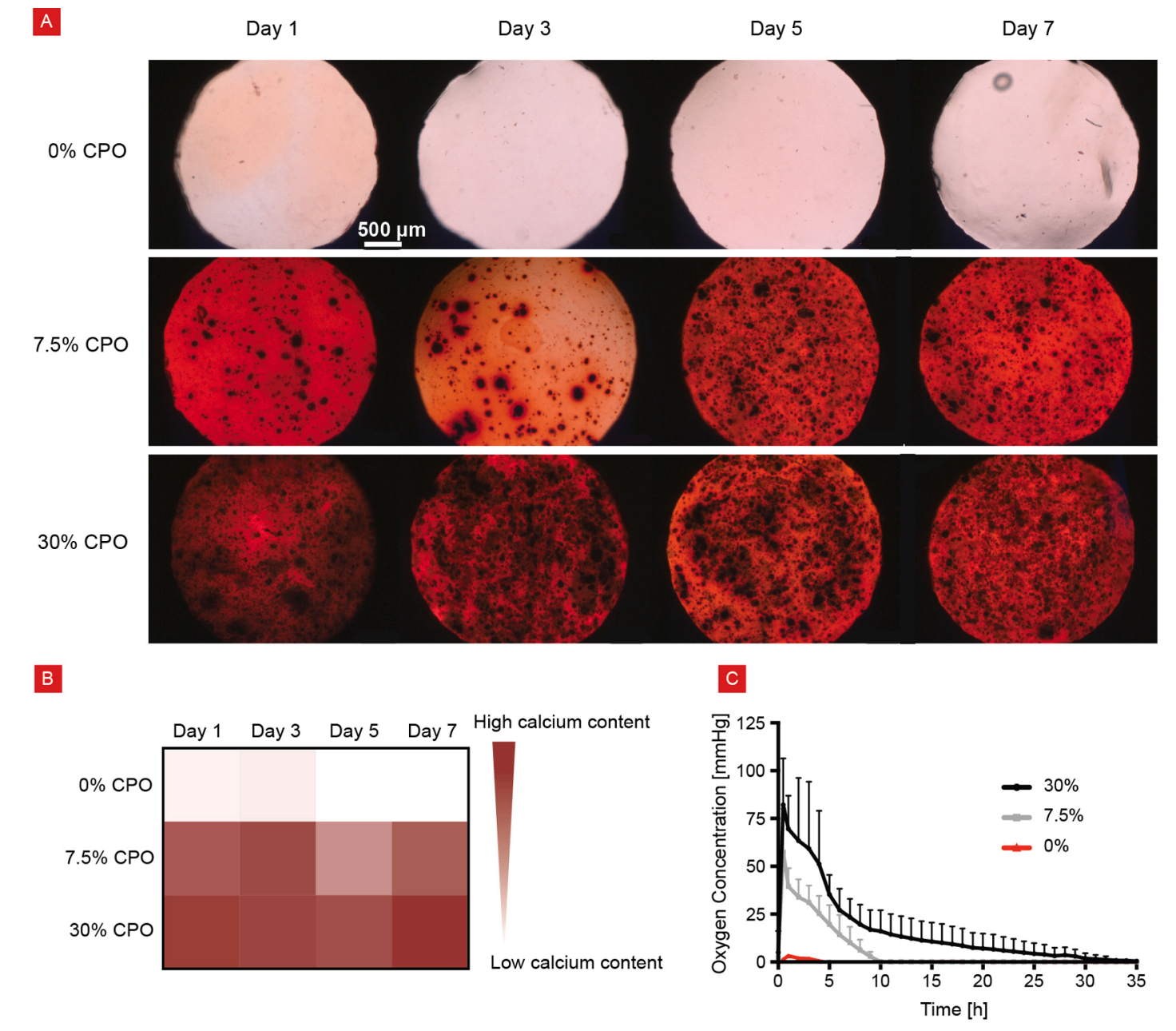

Day 5 Day 7
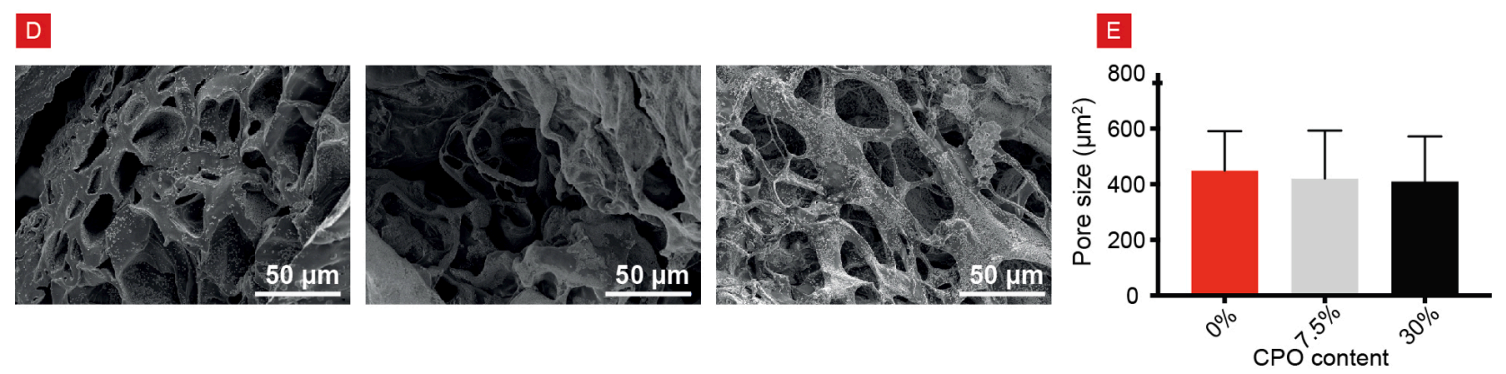

Fig. 3. Hydrogel characterization. A) Representative images of alizarin red staining of hydrogels containing 0, 7.5, and $30 \%$ CPO at different time points B) Colour intensity of stained gels C) Oxygen release kinetics, $n=3$. D) Representative SEM images of hydrogels and E) Measured pore sizes, $n=4$.

other words, CPO significantly increased both the ultimate stress (Supplementary Fig. S4) and toughness of the hydrogels. Additionally, the breakage strain was found to be between 40 and 55\% (Supplementary Fig. S4). The breakage strain of CPO laden hydrogels was found to be significantly increased compared to that of hydrogels without CPO, which makes it into a more load-bearing combination.

The rheological properties for each polymer solution were investigated in terms of gelation point and shear thinning. The gelation point of a polymer solution is the onset of gelation and marks the transition from liquid to solid phase. For polymer solutions containing $0,7.5$, and $30 \%$ $\mathrm{CPO}$ the gelation points were found to be $530 \pm 73,134 \pm 33$, and $41 \pm$ $40 \mathrm{~s}$, respectively (Fig. 4B). Therefore, it was concluded that CPO induces the gelation process and that was in accordance with our previous observations. This can be attributed to a more intensified cross-linking of the hydrogels due to incorporation of CPO. The shear thinning property of the polymer solutions was characterized to assess the injectability of the three combinations. Injectable systems minimize transplantation morbidity and complications by providing a shield which protects cells during the injection and thereby yielding a less invasive method for cell therapy (Thambi et al., 2017). All three polymer solutions were found to exhibit shear thinning properties and therefore, found to be injectable prior to the gelation point. At low shear rates, increased viscosity was also observed for all conditions, which is explained by the initiation of the cross-linking in polymer solutions. This observation was in accordance with the results from the gelation point experiment, confirming an induced gelation process when $\mathrm{CPO}$ was incorporated.

\subsection{Cell viability}

Since the grand goal of our study was to develop a hydrogel system suitable for beta cell therapy, cell viability is a key factor to be 
Mechanical Analysis of HA-CPO Hydrogels
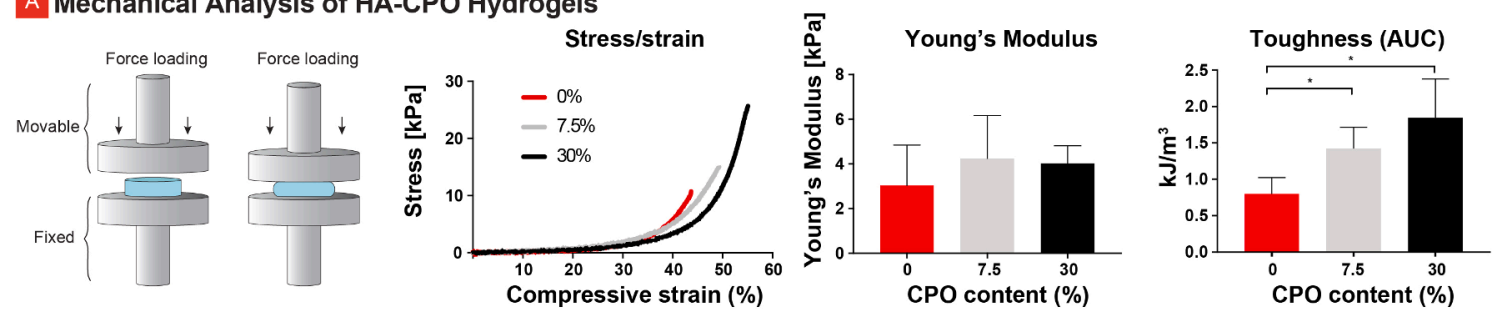

B Rheological Analysis of HA-CPO Hydrogels
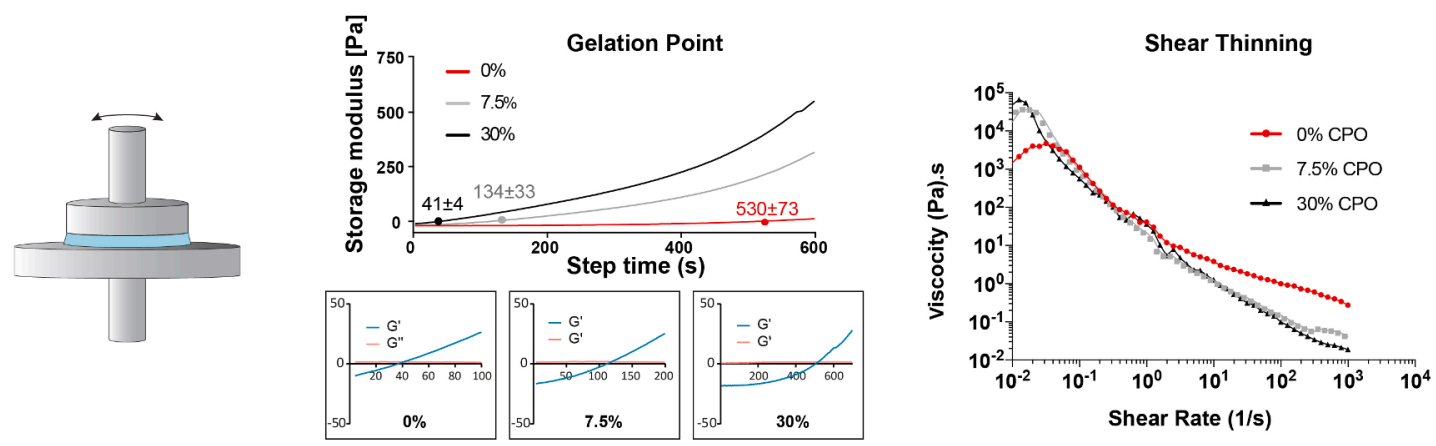

Fig. 4. Mechanical and rheological characterization of hydrogel system. A) Stress/strain curve, Young's modulus, and toughness for hydrogels containing 0 (red), 7.5 (grey), and $30 \%$ (black) $\mathrm{CPO}, \mathrm{n}=5$. B) Gelation point and shear thinning properties for hydrogels of same combinations.

investigated. Before live/dead staining, non-encapsulated and encapsulated clusters were imaged by bright field microscopy, from which it was evident that cells dispersed well within the hydrogels (Fig. 5A).
Before encapsulation, cluster size was measured (Fig. 5B) and the majority of clusters were found to have a diameter below $200 \mu \mathrm{m}$. The distribution of clusters in the hydrogels was assessed, and clusters were

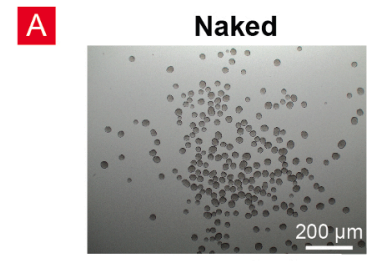

$7.5 \% \mathrm{CPO}$

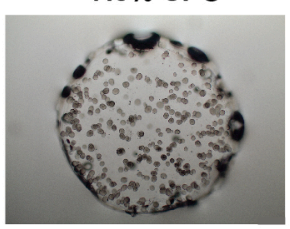

C 0\% CPO
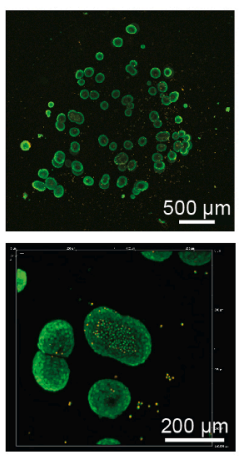

$200 \mu \mathrm{m}$
$7.5 \%$ CPO
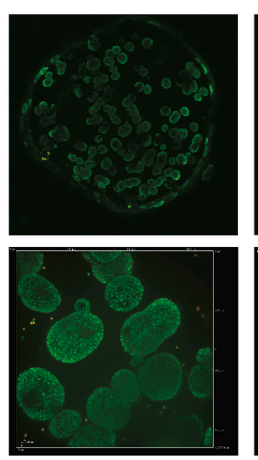

Day 1

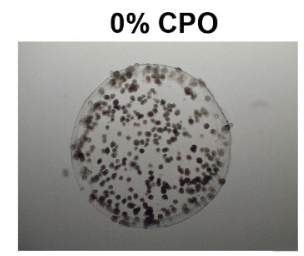

$30 \%$ CPO

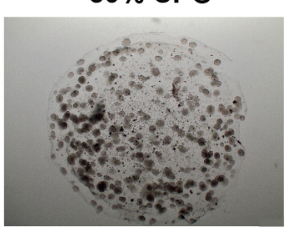

$30 \%$ CPO
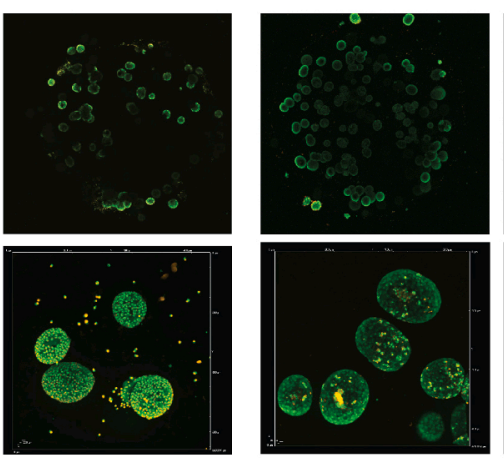

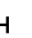

D

0\% CPO

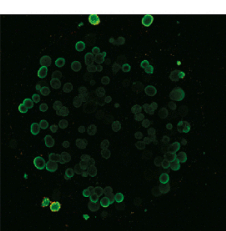

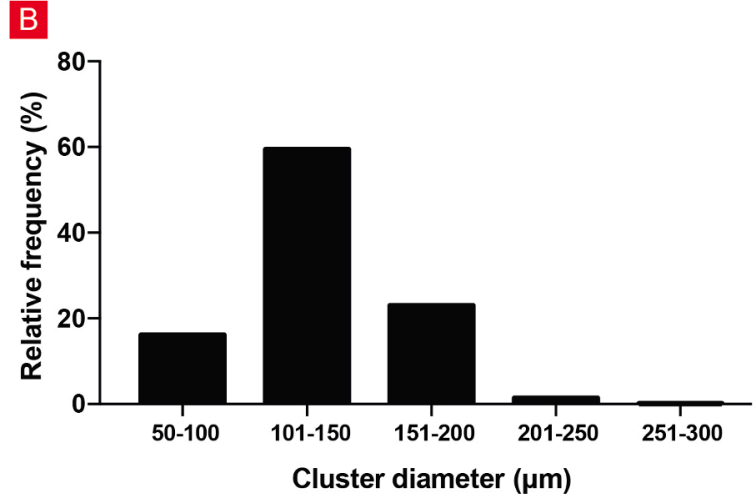

$7.5 \%$ CPO

$30 \%$ CPO
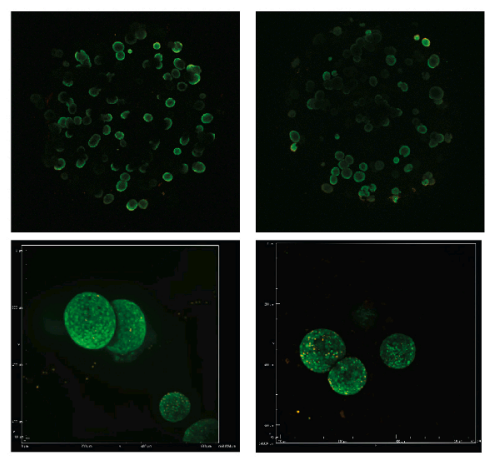

Day 3

Fig. 5. Cell viability. A) Representative bright-field microscopic images of non-encapsulated and encapsulated clusters. B) Cluster size distribution before encapsulation. Representative images of live/dead staining of clusters encapsulated in hydrogels containing 0, 7.5, and 30\% CPO at C) day 1 and D) day 3 The images are an overlay of red and green channel. Live cells were stained green and dead cells were stained red (appear yellow in the overlay images). 
found to be homogenously distributed in both $\mathrm{x}, \mathrm{y}$, and $\mathrm{z}$ direction (Supplementary Fig. S5). Furthermore, fluorescent images were taken to assess the viability of encapsulated INS-1E clusters. At day 1, all encapsulated INS-1E clusters appeared healthy and viable (Fig. 4C) and they were found to be round and symmetric demonstrating that all three hydrogel systems were compatible with INS-1E cells. However, clusters encapsulated in hydrogels without CPO exhibited some dead cells in the center of the clusters, which could be a sign of necrotic centers. Fig. 4D shows the encapsulated clusters at day 3 , demonstrating overall healthy and viable clusters in CPO-laden systems. However, clear necrotic centers were observed in clusters encapsulated in hydrogels without CPO. Clusters encapsulated in CPO laden hydrogels appeared healthy, symmetric and with only a few dead cells. Here, $7.5 \%$ CPO hydrogels were found to yield the highest viability among all conditions.

\subsection{Functionality}

A perifusion set-up was used to characterize and compare the functionality of both encapsulated and non-encapsulated INS-1E clusters. The INS-1E clusters used in these experiments secrete luciferase 1:1 with insulin, and thus cell functionality was assessed by means of luciferase activity. Fig. 6A shows luciferase activity at day 1 normalized to the number of clusters. The clusters were treated with three different input solutions: $2 \mathrm{mM}$ glucose, $20 \mathrm{mM}$ glucose, and $20 \mathrm{mM}$ glucose supplemented with IBMX and forskolin (positive control). The nonencapsulated clusters exhibited, as expected, a transient first phase and a smaller, but sustained second phase during the $20 \mathrm{mM}$ glucose treatment. The first phase of insulin secretion occurs immediately after high glucose stimulation when cells release their readily releasable insulin containing storage granules, whereas the second phase is the transport and release of the reserve pools and the sustained secretion of newly synthesized insulin (Hou et al., 2009). Encapsulation of clusters caused a blunted and delayed first-phase peak compared to nonencapsulated clusters, which can be explained by the limited mass transfer of glucose and luciferase throughout the hydrogel, as will be discussed later.

Fig. 6B shows the total glucose-induced luciferase secretion within $120-215 \mathrm{~min}$. The data is presented as the AUC percentage of the encapsulated clusters compared to the non-encapsulated clusters. The AUC in this time-interval describes the increased secretion when stimulated with glucose (120-154 min) plus any delayed secretion during the following exposure to low glucose (154-215 min). Encapsulated INS- $1 \mathrm{E}$ clusters gave rise to $50 \pm 23,20 \pm 8$, and $14 \pm 9 \%$ luciferase in hydrogels containing $0,7.5$, and $30 \% \mathrm{CPO}$, respectively when compared to non-encapsulated clusters. The luciferase activity of clusters encapsulated in CPO laden hydrogels was found to be lower than the nonencapsulated clusters, indicating that the encapsulation hampers the cell functionality. This observation could be explained by the limited diffusion of oxygen, nutrients, glucose, and luciferase upon encapsulation.

The blood glucose in the human body is tightly regulated by insulin and glucagon, to avoid hyper- and hypo-glycemia. Thus, delays in insulin secretion in response to changing glucose levels, are important to investigate when developing hydrogels for beta cell therapy. The onset of luciferase secretion from encapsulated clusters was found to only be slightly delayed compared to non-encapsulated clusters when stimulated with $20 \mathrm{mM}$ glucose. The peak response was, however, delayed approx. $15 \mathrm{~min}$ when clusters were encapsulated. Accordingly, the time for returning to basal secretion was delayed approx. $20 \mathrm{~min}$ from all three hydrogels $(0,7.5$, and $30 \% \mathrm{CPO})$ when the glucose concentration was lowered to $2 \mathrm{mM}$ (Fig. 6C). The delays are most likely caused by the hampered diffusion of glucose and luciferase throughout the hydrogel compared to liquid medium.

\section{Discussion}

In the field of cell therapy, cell survival is heavily compromised by lack of oxygen at the transplantation site following transplantation. One way to overcome this obstacle is to develop oxygen releasing microenvironments for cell encapsulation that can promote the availability of oxygen and therefore enhance the viability of the transplanted cells. In this study, oxygen releasing hydrogels (incorporated with $0,7.5$, and $30 \%$ CPO) were developed and assessed in terms of chemical and physical properties as well as suitability for beta cell encapsulation.

In this regard, the incorporation of $\mathrm{CPO}$ was confirmed using FTIR analysis and Alizarin red staining. CPO was detected for 3 and 5 days in hydrogels containing 7.5 and $30 \% \mathrm{CPO}$, respectively. Notably, we found that the $\mathrm{CPO}$ and its decomposed product, calcium hydroxide, interacted with the hydrogel matrix most likely via hydrogen bonds or electrostatic interactions, since CPO laden hydrogel gave rise to an increase in the broad $-\mathrm{OH}$ stretching peak between 3000 and $3500 \mathrm{~cm}^{-1}$ (Fig. 2C) over time; something that could be related to the formation of calcium hydroxide. This observation represents the interaction of calcium hydroxide with the hydrogel matrix, since calcium hydroxide is soluble in water. The interaction between $\mathrm{CPO}$, calcium hydroxide and the polymeric matrix was further confirmed by the mechanical compression tests, which showed significantly increased toughness, breakage strain and ultimate stress upon addition of $\mathrm{CPO}$, as a consequence of increased cross-linking. However, $\mathrm{CPO}$ was not found to have any significant effect on Young's modulus of the hydrogels, which was found to perfectly match that of the native pancreatic tissue. Consequently, our systems were found to meet the required physical criteria for beta cell therapy. The mechanical stiffness of the system was found to be greater than what has previously been reported in the literature by Collins and Birkinshaw (Collins and Birkinshaw, 2011) for HA hydrogels. However, this may be explained by the high cross-linking density facilitated by both 8-armPEGA crosslinker and CPO as well as the size of the cross-linker, which increases polymer density, and thereby the systems mechanical properties.

The rheological behavior of the three polymer solutions was analyzed to assess their gelation points and shear thinning properties. Here, we found that the gelation time decreased by the incorporation of
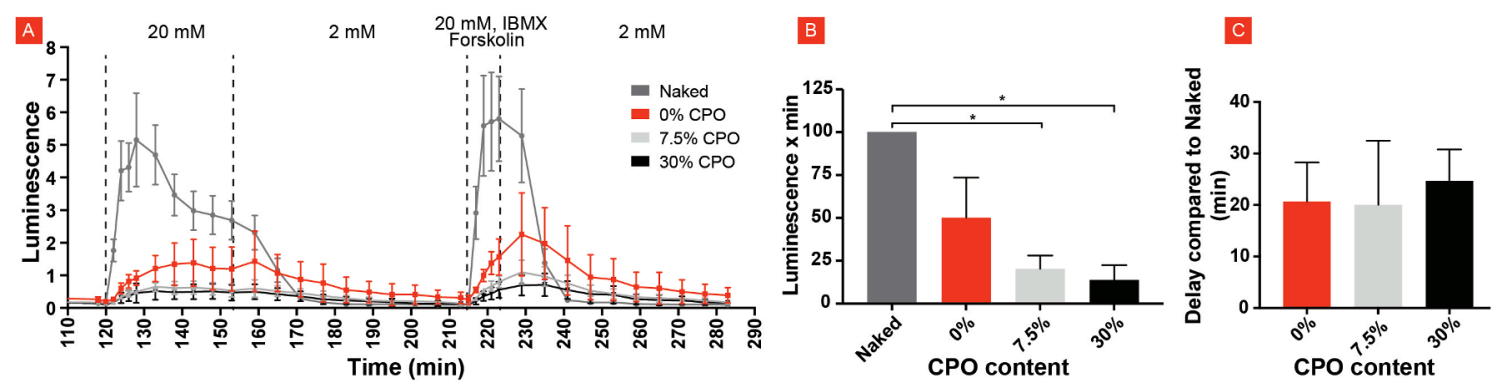

Fig. 6. Cell functionality. A) Real time glucose stimulated luciferase activity at day 1 normalized to number of clusters, $n=3$. B) Area under curve for the $20 \mathrm{mM}$ glucose challenge. C) Responsiveness delay after $20 \mathrm{mM}$ glucose challenge compared to naked clusters. 
CPO. This could be explained by CPO being unstable in aqueous solutions and its fast decomposition into hydrogen peroxide and calcium hydroxide. Hydrogen peroxide induces the cross-linking process of tHA and 8-arm-PEGA by oxidizing the thiol groups of tHA which accelerates the cross-linking process. The intensified cross-linking due to CPO and calcium hydroxide was further evident from Alizarin Red, FTIR, and the mechanical compression studies. All three combinations were found to exhibit shear thinning properties and were thus all found to have injectable properties within the gelation time. However, to fully conclude on the injectability it is important to assess cell survival after injection. This was not done in this study.

From SEM images, the average pore size was found to be smaller than what has previously been reported for tHA-8-arm-PEGA hydrogel system (Hasany et al., 2018), which most probably relates to the sample preparation. Compared to HA hydrogels from Collins and Birkinshaw, our reported pore sizes are significantly smaller, however, this may be attributed to the increased cross-linking and cross-linker density of 8arm-PEGA compared to Collins and Birkinshaw's cross-link system (Collins and Birkinshaw, 2011). Though smaller than previously reported in the literature, the average pore size of the system was found to still allow sufficient exchange of nutrients and waste products to yield high cell survival as evident from the viability study. While CPO was found to affect the mechanical and rheological properties of the hydrogels, it was not confirmed to significantly affect the pore size at 14 h.

The reported oxygen release was relatively rapid compared to other studies (Alemdar et al., 2017), which could be explained by the diffusion of oxygen in water. Once the experiment was finished, hydrogels were found floating on the top of the $3 \mathrm{~mL}$ DPBS. Due to diffusion limitation of oxygen in water it could be speculated that the amount of released oxygen was greater and last longer than reported in Fig. 3C. The FTIR results (Fig. 2D) suggested that $\mathrm{CPO}$ was present for at least 3 and 5 days for hydrogels containing 7.5 and $30 \% \mathrm{CPO}$, respectively. Therefore, it is likely that the relatively short oxygen release was a consequence of the experimental setup. To further prolong the oxygen release presented in this study, matrix hydrophobicity/hydrophilicity and core/shell structures might be considered to create a more controlled oxygen release (Gholipourmalekabadi et al., 2016; Hoare and Kohane, 2008; Xu et al., 2019). A controlled release would decrease the bulk release and instead continuously release oxygen throughout the whole incubation period. The maximum theoretical mass of oxygen that can be produced from the amount of CPO incorporated in the hydrogels, was calculated to be 2.5 and $10 \mu \mathrm{g}$ oxygen for 7.5 and $30 \% \mathrm{CPO}$, respectively, in a $30 \mu \mathrm{L}$ hydrogel. The release experiment was carried out in $3 \mathrm{~mL}$ of DPBS and the maximum oxygen concentration would, therefore, be $0.8 \mathrm{mg} / \mathrm{L}$ for $7.5 \% \mathrm{CPO}$ and $3.3 \mathrm{mg} / \mathrm{L}$ for $30 \% \mathrm{CPO}$ corresponding to approx. 14 and $56 \mathrm{mmHg}$, respectively. Fig. $3 \mathrm{C}$ indicates that the initial burst release of oxygen was greater than the calculated theoretical maximum oxygen concentration. This could be explained by the limited oxygen diffusion in water and the experimental setup. The oxygen sensor was placed at the bottom of the vial where the hydrogel initially was placed. The concentration was calculated based on the $3 \mathrm{~mL}$ sample volume. However, a compromised oxygen diffusion might have resulted in a nonhomogenous distribution of oxygen within the liquid (Wenger et al., 2015). Thus, resulting in accumulation and a higher oxygen concentration at the bottom of the vial, where both the hydrogel and sensor were located.

Catalase was added to the culture medium to avoid accumulation of hydrogen peroxide and thus lead to potential cytotoxic levels. However, the maximum amount of hydrogen peroxide produced from the developed scaffolds was $20 \mu \mathrm{M}$, which is below the cytotoxicity level of many cell types (Halliwell et al., 2000).

Cell viability was investigated to assess whether $\mathrm{CPO}$ had a positive effect on cell survival. Likewise, it was important to examine if either the exothermic reaction of CPO decomposition or its product hydrogen peroxide had any negative effects on the encapsulated cluster. The hydrogel systems were all found to be compatible with the encapsulated INS-1E clusters. We observed necrotic centers at day 1 and 3 in clusters encapsulated in CPO-free hydrogels, most likely due to the restricted oxygen diffusion through the cell cluster and formation of hypoxic conditions in the core, which leads to development of central necrosis in the clusters (Komatsu et al., 2017, 2018). Therefore, the observed necrotic centers were attributed to oxygen limitation upon encapsulation. On the other hand, no necrotic centers were observed from clusters encapsulated in CPO laden hydrogels and the incorporation of CPO did, as hypothesized, positively affect the cell survival for at least 3 days of culture. Pancreatic beta cells are sensitive to oxidative stress as they produce low levels of antioxidant enzymes such as catalase (Bloch et al., 2007). In this study, we added catalase to the culture medium to avoid accumulation of hydrogen peroxide in the culture and mimic the in vivo environment where catalase is naturally present. For future studies it would be essential to assess the viability of encapsulated clusters cultured without catalase and to incorporate catalase in the hydrogel system to minimize any cytotoxic effects caused by hydrogen peroxide.

The functionality study confirmed that all encapsulated clusters were functional, however the functionality was found to be reduced upon encapsulation. The lack of a fast first phase peak observed from the encapsulated clusters, could be explained by the 3D structure of the hydrogel. Since the clusters were distributed in a 3D micro-environment, it is plausible that glucose reached the encapsulated clusters at different time points, thereby giving rise to a non-synchronized first-phase response from individual clusters in the hydrogel. So, the onset of luciferase secretion from encapsulated clusters in the periphery of the gel was similar to that of non-encapsulated clusters, however, the maximum luciferase activity was delayed, and the total secretion was lowered. This observation was seen from both $20 \mathrm{mM}$ glucose challenge and the IBMX/forskolin challenge. Both limited secretory output in response to glucose stimulation and the delayed and blunted first-phase peak have previously been reported in the literature to be due to encapsulation causing extra resistance towards diffusion of both inputs and outputs. As an example, Buchwald and coworkers reported limited insulin secretion and a delayed blunted first-phase peak in response to encapsulation of murine and human islets in calcium cross-linked alginate micro-beads (Buchwald et al., 2018). If transplanted in vivo, a significant delay introduced by encapsulation might lead to hyper- or hypoglycemic conditions in the patient, which consequently may cause adverse effects (Arieff et al., 1974). Therefore, the delays need to be further assessed in vivo, to determine whether they cause any physiological effects.

The decreased functionality (Fig. 6B) caused by incorporation of increasing CPO concentrations may be explained by the hydrogel matrix: Results from FTIR, Alizarin Red, and mechanical studies demonstrated that $\mathrm{CPO}$ and calcium hydroxide interacted with the cross-linked polymeric network and thereby intensified the cross-linking of the system. Though no significant effect on the pore size was observed, this may have introduced an increased diffusion limitation of oxygen, glucose, and luciferase, compared to the hydrogels without CPO, thus negatively affecting the functionality. Although the cluster viability seems to be positively affected by increasing oxygen release by increasing CPO incorporation, it may not support sufficient oxygen to maintain full functionality during the perifusion experiment. This is supported by the observation that beta-cells demand higher oxygen levels to function compared to surviving (Colton, 2014). Another fact that is important to mention is, that hydrogen peroxide have been reported to hamper insulin secretion under glucose stimulatory concentrations (Llanos et al., 2015). Catalase was not added to the KRBH-buffer during the functionality study, which may have negatively affected the functionality of clusters encapsulated in CPO-laden hydrogels.

For future studies, it would be interesting to investigate how a less cross-linked hydrogel structure might affect cell functionality and whether catalase is necessary for the clusters to function in a CPO-laden hydrogel. Additionality, it would be of interest to assess viability and 
functionality of encapsulated human islets or stem cell derived beta-cell like clusters, as these are more relevant for future beta cell therapies than INS-1E. Human islets have, furthermore, been reported to have a lower oxygen consumption rate (OCR) at high glucose stimulation compared to INS-1E clusters (Supplementary Fig. S6) (Kitzmann et al., 2014), which might positively affect the functionality of the encapsulated cells.

\section{Conclusion}

Cell therapy has shown promising results for treatment of type 1 diabetes. However, injection based

cell administration has shown low post transplantation viability rates. The aim of this study was to develop an oxygen releasing hydrogel system suitable for beta cell therapy to overcome this challenge. Varying concentrations of CPO were successfully incorporated into hydrogels, and the mechanical properties of the CPO-modified hydrogels were observed to match those of the native pancreatic tissue. CPOincorporated samples were further found to maintain cells viable and healthy for at least 3 days of culture, and the formation of necrotic centres in encapsulated cell clusters was reduced compared to samples without CPO. Though showing great viability of the encapsulated clusters, the cell functionality was found to be compromised, pointing at a prolonged oxygen release profile and improved diffusion properties as important parameters to improve. In conclusion, this study suggests that the physiochemical properties of CPO-containing HA-8-arm-PEGA hydrogels make them a promising candidate for beta cell therapy by protecting the cells from sheer stress and the deleterious effects of hypoxia at the transplantation site.

\section{CRediT authorship contribution statement}

Mette Steen Toftdal: Conceptualization, Investigation, Writing original draft. Nayere Taebnia: Investigation, Validation. Firoz Babu Kadumudi: Formal analysis, Supervision, Writing - review \& editing. Thomas Lars Andresen: Resources, Writing - review \& editing. Thomas Frogne: Validation, Resources, Writing - review \& editing. Louise Winkel: Validation, Resources, Writing - review \& editing. Lars Groth Grunnet: Validation, Resources, Supervision, Writing - review \& editing. Alireza Dolatshahi-Pirouz: Project administration, Supervision, Writing - review \& editing.

\section{Declaration of Competing Interest}

The authors declare that they have no known competing financial interests or personal relationships that could have appeared to influence the work reported in this paper.

\section{Acknowledgements}

ADP would like to acknowledge the Villum Foundation (10103) and the VIDI research program with project number R0004387, which is (partly) financed by the Netherlands Organization for Scientific Research (NWO). The authors further wish to thank Marianne Vollmond for excellent technical assistance and Johannes Josef Fels and Tine Østergaard for conducting the insulin quantification measurements.

\section{Appendix A. Supplementary material}

Supplementary data to this article can be found online at https://doi. org/10.1016/j.ijpharm.2021.120595.

\section{References}

Agashi, K., Chau, D.Y., Shakesheff, K.M., 2009. The effect of delivery via narrow-bore needles on mesenchymal cells.
Alemdar, N., Leijten, J., Camci-Unal, G., Hjortnaes, J., Ribas, J., Paul, A., Mostafalu, P., Gaharwar, A.K., Qiu, Y., Sonkusale, S., 2017. Oxygen-generating photo-crosslinkable hydrogels support cardiac progenitor cell survival by reducing hypoxiainduced necrosis. ACS Biomater. Sci. Eng. 3, 1964-1971.

Arieff, A.I., Doerner, T., Zelig, H., Massry, S.G., 1974. Mechanisms of Seizures and Coma in Hypoglycemia Evidence for a direct effect of insulin on electrolyte transport in brain. J. Clin. Investig. 54, 654-663.

Association, A.D., 2018. 2. Classification and diagnosis of diabetes: standards of medical care in diabetes-2018. Diabetes Care 41, S13-S27.

Bloch, K., Shichman, E., Vorobeychik, M., Bloch, D., Vardi, P., 2007. Catalase expression in pancreatic alpha cells of diabetic and non-diabetic mice. Histochem. Cell Biol. 127, 227-232.

Buchwald, P., Tamayo-Garcia, A., Manzoli, V., Tomei, A.A., Stabler, C.L., 2018. Glucosestimulated insulin release: parallel perifusion studies of free and hydrogel encapsulated human pancreatic islets. Biotechnol. Bioeng. 115, 232-245.

Burns, S.M., Vetere, A., Walpita, D., Dančík, V., Khodier, C., Perez, J., Clemons, P.A., Wagner, B.K., Altshuler, D., 2015. High-throughput luminescent reporter of insulin secretion for discovering regulators of pancreatic Beta-cell function. Cell Metab. 21, 126-137.

Camci-Unal, G., Alemdar, N., Annabi, N., Khademhosseini, A., 2013. Oxygen-releasing biomaterials for tissue engineering. Polym. Int. 62, 843-848.

Cho, N., Shaw, J., Karuranga, S., Huang, Y., da Rocha Fernandes, J., Ohlrogge, A., Malanda, B., 2018. IDF Diabetes Atlas: Global estimates of diabetes prevalence for 2017 and projections for 2045. Diabetes Res. Clin. Pract. 138, 271-281.

Chung, S., Lee, H., Kim, H.-S., Kim, M.-G., Lee, L.P., Lee, J.Y., 2016. Transdermal thiol-acrylate polyethylene glycol hydrogel synthesis using near infrared light. Nanoscale 8, 14213-14221.

Collins, M.N., Birkinshaw, C., 2011. Morphology of crosslinked hyaluronic acid porous hydrogels. J. Appl. Polym. Sci. 120, 1040-1049.

Colton, C.K., 2014. Oxygen supply to encapsulated therapeutic cells. Adv. Drug Deliv. Rev. 67, 93-110.

Davalli, A.M., Ogawa, Y., Ricordi, C., Scharp, D., Bonner-Weir, S., Weir, G., 1995. A selective decrease in the beta cell mass of human islets transplanted into diabetic nude mice. Transplantation 59, 817-820.

Derakhshanfar, S., Mbeleck, R., Xu, K., Zhang, X., Zhong, W., Xing, M., 2018. 3D bioprinting for biomedical devices and tissue engineering: A review of recent trends and advances. Bioact. Mater. 3, 144-156.

D'souza, Shegokar, 2016. Polyethylene glycol (PEG): a versatile polymer for pharmaceutical applications. Expert Opin. Drug Deliv. 13, 1257-1275. https://doi. org/10.1080/17425247.2016.1182485.

Fowler, M.J., 2008. Microvascular and macrovascular complications of diabetes. Clinical diabetes $26,77-82$.

Gholipourmalekabadi, M., Zhao, S., Harrison, B.S., Mozafari, M., Seifalian, A.M., 2016. Oxygen-generating biomaterials: a new, viable paradigm for tissue engineering? Trends Biotechnol. 34, 1010-1021.

Group, DCCT/EDIC., 2005. Intensive diabetes treatment and cardiovascular disease in patients with type 1 diabetes. N. Engl. J. Med. 353, 2643-2653.

Halliwell, B., Clement, M.V., Long, L.H., 2000. Hydrogen peroxide in the human body. FEBS Lett. 486, 10-13.

Haraguchi, Y., Shimizu, T., Yamato, M., Okano, T., 2012. Concise review: cell therapy and tissue engineering for cardiovascular disease. Stem Cells Trans. Med. 1 $136-141$.

Hasany, M., Thakur, A., Taebnia, N., Kadumudi, F.B., Shahbazi, M.-A., Pierchala, M.K., Mohanty, S., Orive, G., Andresen, T.L., Foldager, C.B., 2018. Combinatorial Screening of Nanoclay-Reinforced Hydrogels: A Glimpse of the "Holy Grail" in Orthopedic Stem Cell Therapy? ACS Appl. Mater. Interfaces 10, 34924-34941.

Hoare, T.R., Kohane, D.S., 2008. Hydrogels in drug delivery: Progress and challenges. Polymer 49, 1993-2007.

Hou, J.C., Min, L., Pessin, J.E., 2009. Insulin granule biogenesis, trafficking and exocytosis. Vitam. Horm. 80, 473-506.

Jain, E., Hill, L., Canning, E., Sell, S.A., Zustiak, S.P., 2017. Control of gelation, degradation and physical properties of polyethylene glycol hydrogels through the chemical and physical identity of the crosslinker. J. Mater. Chem. B 5, 2679-2691.

Khorshidi, S., Karkhaneh, A., Bonakdar, S., 2020. Fabrication of amine-decorated nonspherical microparticles with calcium peroxide cargo for controlled release of oxygen. J. Biomed. Mater. Res. Part A 108, 136-147.

Kitzmann, J., Karatzas, T., Mueller, K., Avgoustiniatos, E., Gruessner, A.C., Balamurugan, A., Bellin, M., Hering, B., Papas, K.K., 2014. Islet preparation purity is overestimated, and less pure fractions have lower post-culture viability before clinical allotransplantation. Transplant. Proc. 1953-1955.

Komatsu, H., Cook, C., Wang, C.-H., Medrano, L., Lin, H., Kandeel, F., Tai, Y.-C., Mullen, Y., 2017. Oxygen environment and islet size are the primary limiting factors of isolated pancreatic islet survival. PLoS ONE 12, e0183780.

Komatsu, H., Kandeel, F., Mullen, Y., 2018. Impact of oxygen on pancreatic islet survival. Pancreas 47, 533.

Llanos, P., Contreras-Ferrat, A., Barrientos, G., Valencia, M., Mears, D., Hidalgo, C., 2015. Glucose-dependent insulin secretion in pancreatic $\beta$-cell islets from male rats requires Ca $2+$ release via ROS-stimulated ryanodine receptors. PLoS ONE 10, e0129238.

Ludwig, B., Ludwig, S., Steffen, A., Knauf, Y., Zimerman, B., Heinke, S., Lehmann, S., Schubert, U., Schmid, J., Bleyer, M., 2017. Favorable outcome of experimental islet xenotransplantation without immunosuppression in a nonhuman primate model of diabetes. Proc. Natl. Acad. Sci. 114, 11745-11750.

Mahinroosta, M., Farsangi, Z.J., Allahverdi, A., Shakoori, Z., 2018. Hydrogels as intelligent materials: A brief review of synthesis, properties and applications. Mater. Today Chem. 8, 42-55. 
McQuilling, J.P., Sittadjody, S., Pendergraft, S., Farney, A.C., Opara, E.C., 2017. Applications of particulate oxygen-generating substances (POGS) in the bioartificial pancreas. Biomater. Sci. 5, 2437-2447.

Montesdeoca, C.Y.C., Afewerki, S., Stocco, T.D., Corat, M.A.F., de Paula, M.M.M., Marciano, F.R., Lobo, A.O., 2020. Oxygen-generating smart hydrogels supporting chondrocytes survival in oxygen-free environments. Colloids Surf., B 194, 111192.

Mouré, A., Bacou, E., Bosch, S., Jegou, D., Salama, A., Riochet, D., Gauthier, O., Blancho, G., Soulillou, J.P., Poncelet, D., 2019. Extracellular hemoglobin combined with an $\mathrm{O} 2$-generating material overcomes $\mathrm{O} 2$ limitation in the bioartificial pancreas. Biotechnol. Bioeng. 116, 1176-1189.

Organization, W.H., 2016. Global report on diabetes.

Rastinfard, A., Nazarpak, M.H., Moztarzadeh, F., 2018. Controlled chemical synthesis of $\mathrm{CaO} 2$ particles coated with polyethylene glycol: characterization of crystallite size and oxygen release kinetics. RSC Adv. 8, 91-101.

Rezania, A., Bruin, J.E., Arora, P., Rubin, A., Batushansky, I., Asadi, A., O'dwyer, S., Quiskamp, N., Mojibian, M., Albrecht, T., 2014. Reversal of diabetes with insulinproducing cells derived in vitro from human pluripotent stem cells. Nat. Biotechnol. $32,1121$.

Segura, Anderson, Chung, Webber, Shull, Shea, 2005. Crosslinked hyaluronic acid hydrogels: a strategy to functionalize and pattern. Biomaterials 26 (4), 359-371. https://doi.org/10.1016/j.biomaterials.2004.02.067.

Sugimoto, M., Takahashi, S., Kojima, M., Gotohda, N., Kato, Y., Kawano, S., Ochiai, A. Konishi, M., 2014. What is the nature of pancreatic consistency? Assessment of the elastic modulus of the pancreas and comparison with tactile sensation, histology, and occurrence of postoperative pancreatic fistula after pancreaticoduodenectomy. Surgery 156, 1204-1211.

Thambi, T., Li, Y., Lee, D.S., 2017. Injectable hydrogels for sustained release of therapeutic agents. J. Control. Release 267, 57-66.

Weber, L.M., Lopez, C.G., Anseth, K.S., 2009. Effects of PEG hydrogel crosslinking density on protein diffusion and encapsulated islet survival and function. J. Biomed. Mater. Res. Part A: Off. J. Soc. Biomate. Jpn. Soc. Biomater. Aust. Soc. Biomater. Korean Soc. Biomater. 90, 720-729.

Wenger, R.H., Kurtcuoglu, V., Scholz, C.C., Marti, H.H., Hoogewijs, D., 2015. Frequently asked questions in hypoxia research. Hypoxia 3, 35.

Wolf, K.J., Kumar, S., 2019. Hyaluronic acid: incorporating the bio into the material. ACS Biomater. Sci. Eng. 5, 3753-3765.

Xu, R., Zhang, Z., Toftdal, M.S., Møller, A.C., Dagnaes-Hansen, F., Dong, M., Thomsen, J. S., Brüel, A., Chen, M., 2019. Synchronous delivery of hydroxyapatite and connective tissue growth factor derived osteoinductive peptide enhanced osteogenesis. J. Control. Release 301, 129-139.

Zamboni, F., Collins, M.N., 2017. Cell based therapeutics in type 1 diabetes mellitus. Int. J. Pharm. 521, 346-356.

Zamboni, F., Ryan, E., Culebras, M., Collins, M.N., 2020. Labile crosslinked hyaluronic acid via urethane formation using bis ( $\beta$-isocyanatoethyl) disulphide with tuneable physicochemical and immunomodulatory properties. Carbohydr. Polym. 245, 116501.

Zarembinski, T.I., Skardal, A., 2018. HyStem ${ }^{\circledR}$ : a unique clinical grade hydrogel for present and future medical applications, Hydrogels-Smart Materials for Biomedical Applications. IntechOpen. 